\title{
Introduction
}

Jack E Henningfield

Clinical

Pharmacology

Branch, National

Institute on Drug

Abuse, Addiction

Research Center, PO

Box 5180, Baltimore,

Maryland 21224, USA

$\mathrm{J}$ E Henningfield
I shall be your next presenter on our current goal of smoking cessation, but I should first like to introduce my fellow presenters, Drs Reuter and Hughes, and my panelists, Drs Hurt, Rand, and Vocci.

Peter Reuter is a professor of the School of Public Affairs at the University of Maryland, and head of the social policy specialisation programme there. Before coming to Maryland, Dr Reuter was the co-director of the Drug Policy Research Center of the RAND Corporation, and there he led the multidisciplinary research programme that covered the entire range of drug policy issues from epidemiology to crop eradication. $\mathrm{He}$ is one of the harm reduction "warriors". He has been one of the people that have seen first hand why this is a controversial issue, and he will show that there are some controversies that may apply to tobacco and others that may not as readily apply.

John R Hughes is a professor of Psychiatry, Psychology, and Family Practice at the University of Vermont in Burlington. He is the current president of the Society for Research on Nicotine and Tobacco and the chair of the nicotine dependenice task force and nicotine dependence treatment guidelines committee for the American Psychiatric Association.
Richard D Hurt is the director of the Nicotine Dependence Center and chair of the Division of Community Internal Medicine at the Mayo Clinic in Rochester, Minnesota. $\mathrm{He}$ has performed innovative research on effective smoking interventions and has developed a model for what comprehensive smoking cessation in a hospital could be, ranging from inpatient to community intervention approaches.

Cynthia S Rand is an associate professor of Medicine in the School of Medicine, Division of Pulmonary and Critical Care Medicine at the Johns Hopkins University. She has been heavily involved in smoking cessation research, including the lung health study, which gave her some special insights in what happens in large populations when you are trying to monitor them and when they have access to nicotine replacement over a long period of time.

Frank J Vocci is the deputy director of the Medication Development Division of the National Institute on Drug Abuse. He was also at Food and Drug Administration when nicotine polacrilex, or gum, was approved, and he now sees these issues both through the perspectives of other drugs and from the perspective of nicotine.

\section{Introduction to tobacco harm reduction as a complementary strategy to smoking cessation}

\author{
Jack E Henningfield
}

Reducing the prevalence of tobacco use through prevention and treatment efforts is universally supported by health professionals because of the enormous potential for reducing the devastating public health effects of tobacco use. In contrast, efforts to reduce the adverse effects of tobacco in those who continue to smoke have generally been viewed as ineffective and counterproductive. Recent data and projections suggest that this latter assumption needs re-evaluation.

\section{Pharmacology}

Branch, National

Institute on Drug

Abuse, Addiction

Research Center, PO

Box 5180, Baltimore,

Maryland 21224, USA

$\mathrm{J}$ E Henningfield

Correspondence to: Dr Jack E Henningfield.
Background

In the United States, the prevalence of cigarette smoking has been relatively stable at about $26-27 \%$ for nearly five years, and smoking by youth has been stable or possibly even increasing over the past decade. ${ }^{1-3}$ Thus, in the absence of a dramatic lowering of prevalence of tobacco use or of the consequences of its use, more than one million people will continue to die prematurely every two to three years for many years to come, and many millions more will suffer unnecessarily and be disabled by tobacco. ${ }^{4}$

The worldwide scenario is even bleaker. Annual morbidity is expected to increase from three million per year to 10 million per year over the next two decades, with half a billion of the world's current population dying of tobacco related disease. ${ }^{4}$ Some of these deaths will be among non-smokers who cannot escape environmental smoke because of the high prevalence of smoking.

These grim projections do not detract from 
the considerable success of public health efforts, nor do they suggest that we should diminish efforts that have proved effective at reducing the prevalence of smoking in the United States from its all time high levels in the 1960s. However, the evidence that progress has slowed in the USA and that tobacco addiction and its associated diseases continue to increase worldwide supports the need for a re-examination of strategies to reduce the death and disease caused by tobacco use. The present paper and those that follow will provide an overview of some of the issues and unanswered questions.

\section{The means versus the ends}

The two primary means of reducing tobaccocaused death and disease are prevention of use and treatment of dependent persons. These efforts produced the first documented downturn in tobacco-caused mortality in the USA in 1990 and they are important to sustain. ${ }^{5}$ However, as has been discussed elsewhere, ${ }^{6}$ reducing tobacco-caused death and disease is the long range goal; strategies such as cessation treatment are a means and not necessarily the only means. Other means might include substantially expanded approaches to prevention and a broadening of the range of options for nicotine dependent tobacco users. Reducing the risk of harm in people who continue to smoke is an approach to be considered in this paper.

\section{Individual versus population effects of harm reduction}

It is important to recognise that harm reduction at the individual level does not necessarily go hand in hand with reduction at a population level. For example, individuals who sustain their nicotine addiction by smoking cigarettes might lessen their risk of tobaccocaused death and disability by switching to a smokeless tobacco product. Unfortunately, the expanded marketing and broad perception of relative safety of smokeless tobacco products contributed to the explosive rise in smokeless tobacco use among young people in the United States from the 1970 s to 1980 s, and this appeared to have had little or no effect on reducing cigarette smoking among the young. ${ }^{2,7,8}$ Thus, although some individuals might have somewhat reduced their tobacco toxin intake by switching from cigarettes to smokeless tobacco, the health of the nation suffered. Similarly, the promotion of the theoretically less toxic filtered cigarette has been attributed to helping to sustain the high prevalence of smoking - and thus morbidity and mortality - at the population level. ${ }^{9}$ It is therefore questionable whether smokeless tobacco or new cigarette types could be considered viable as harm reduction approaches.

In contrast to the use of tobacco products in harm reduction approaches, an expanded use of nicotine-delivering preparations might be effective at reducing harm by individual tobacco users as well as in the population. The nicotine replacement preparations studied to date do not contain the highly toxic substances provided by tobacco products, do not provide the explosive bursts of highly concentrated nicotine doses to the arterial blood stream that cigarettes do, and appear to be substantially less capable of causing new addiction problems or sustaining addiction compared to tobacco products. ${ }^{10-12}$ Data reported in hearings before the US Food and Drug Administration (FDA), in July 1992 indicated that despite the fact that many people who were prescribed nicotine transdermal systems continued to smoke, most appeared to do so at reduced levels and the incidence of heart attacks among transdermal users was several orders of magnitude lower than expected in the general population.

\section{Assessment of harm reduction}

Traditionally, smoking cessation efforts are assessed by dichotomous measures: any evidence of smoking results in categorisation of the patient as a treatment failure. Harm reduction approaches require attention to a broader range of outcome variables. For example, at the individual level, proxy or surrogate measures such as amount of tobacco consumed and systemic levels of tobaccorelated toxins, as well as direct measures of toxicity such as lung and cardiovascular function, can be assessed. At the population level, assessing the impact of harm reduction approaches may require closer attention to outcome measures such as per capita cigarette consumption, per smoker cigarette consumption, per tobacco user consumption of all forms of tobacco, and the percentage of smokers who are "chippers" (people who smoke less than five cigarettes per day). For example, for many years in the United States, chippers have comprised about $10-15 \%$ of the tobacco using population. ${ }^{10}$ One potentially beneficial outcome of a harm reduction strategy would be to increase the proportion of tobacco users who smoke at such low levels. These are just a few of the measurement and study design issues that need to be addressed as harm reduction strategies are considered.

\section{Complementary prevention approaches}

Expanded prevention approaches could also contribute to reduced prevalence of addictive smoking. It appears that earlier onset of tobacco use is associated with more severe subsequent dependence than delayed onset of tobacco use. ${ }^{13}$ This observation is similar to that regarding other addictive drugs, ${ }^{14,15}$ and suggests the expansion of prevention approaches aimed specifically at delaying the age of onset of any use, as well as imposing barriers to delay the transition from occasional use to regular use. These goals are especially important in light of the fact that approximately two thirds of all adolescents in the USA continue to sample cigarettes and one third to one half of these children develop dependence. $^{2,3,16,17}$

Another approach would be to prevent the 
transition to high levels of addiction in those young people who have begun to smoke regularly. This would require the development of treatment interventions targeted towards the needs of young tobacco users. ${ }^{18}$ The fact that nearly $40 \%$ of adolescent smokers report some level of interest in youth-targeted smoking cessation programmes supports the development of such programmes. ${ }^{19}$

Tobacco product and regulatory changes might also contribute to prevention efforts. For example, more accurate labelling of the delivery of nicotine and tar on cigarettes might enable consumers to control and reduce their intake of such chemicals more effectively. ${ }^{20}$ In addition, if the nicotine content of cigarettes was reduced to levels that were not sufficient to cause or sustain addiction, then, even among young people who take up cigarette smoking, later efforts to quit smoking upon reaching adulthood would not be complicated by the presence of nicotine addiction. ${ }^{21}$ These and other new prevention approaches might be considered along with new treatment approaches, since a fundamental public health aim is to coordinate prevention and treatment strategies to maximise the impact of each.

\section{Complementary treatment approaches: harm reduction}

Effective cessation interventions, such as nicotine replacement, may be considered major medical treatment advances because they increase the likelihood of successful long term cigarette abstinence by three- to fourfold over the $\sim 7 \%$ rates of success achieved by people who quit on their own. On the other hand, most people given any form of smoking cessation treatment relapse to heavy addictive cigarette smoking; their needs do not appear to be adequately addressed by current approaches, and treatment may be terminated if they resume smoking. One solution is to "recycle" such patients into new treatment programmes. ${ }^{22}$

A complementary approach to the foregoing is to expand the range of treatment options and goals. An example of this is the potential for different indications for medications for treating nicotine dependence which have been proposed to the FDA. ${ }^{23}$ Those proposed indications are:

(1) Relieve withdrawal

(2) Decrease use/achieve abstinence

(3) Prevent relapse

(4) Reverse toxic effects

These indications are similar to those proposed for treatments targeted at other disorders of psychoactive substance use, such as cocaine, opioid, and alcohol dependence. The first three indications appear to be viable targets for existing treatments; however, important questions need to be resolved by data collection. For example, would enabling people to achieve intermittent tobacco abstinence to meet occupational demands by treating withdrawal symptoms increase or decrease the likelihood that they will ultimately stop smoking? Simi- larly, the protracted use of replacement medications to produce what might be termed "partial tobacco abstinence" or "major smoking reduction" has not been studied as an endpoint in its own right, even though substantial smoking reduction has often been reported as a byproduct of cessation efforts (for example, see ${ }^{24}$ ). Finally, the protracted use of medicines to sustain remission and prevent relapse is widely practised in other areas of medicine but has not been systematically studied as a potential approach to treating tobacco dependence. Perhaps it should be.

\section{Concluding comments}

As harm reduction approaches to tobacco use are considered in the papers by Reuter and Hughes in this supplement and in the accompanying discussion, it should be apparent that such approaches can differ widely in form and effect for individuals and populations. Rather than simply accepting or dismissing harm reduction approaches, the risks and benefits of each approach should be compared and contrasted. Similarly, when looking at other addictive drugs for insights into the potential risks and benefits of such approaches with respect to tobacco addiction, ${ }^{25}$ it is important to consider the differences in the pharmacology and toxicology of the substances that may also limit the applicability of any conclusions reached (see discussion of such issues by Goldstein ${ }^{26}$ ).

Finally, it is apparent that important unanswered questions about the viability and impact of various harm reduction approaches limit the accuracy of predictions. ${ }^{27}$ Therefore, this paper and those that follow should be considered as early steps in a process that may lead to new approaches to lessening the death and disability toll of tobacco. Ideally, such approaches should strengthen the impact of the existing prevention and treatment approaches that have proven effective.

Other issues are also relevant to these discussions. For example, how would making a nicotine replacement treatment available overthe-counter affect its value in cessation and harm reduction interventions? What would be the advantages and disadvantages of nonnicotine-delivering medications for harm reduction compared to nicotine-delivering medications? How would treatment goals such as "partial tobacco abstinence" affect the broader goal of reduced population prevalence of tobacco use? Should products developed and marketed by tobacco companies, which differ substantially from conventional tobacco products (for example, RJ Reynolds's Premier and Eclipse products) be exempted from the sort of regulatory oversight given to foods and drugs?

These and many other issues will be discussed in the following papers and accompanying discussion. Few, if any of the issues are likely to be resolved at this time. However, it would appear that the time has come to re-evaluate our goals and strategies if we are to produce further reductions in smoking-caused disease 
in the United States and to reverse the escalating growth of tobacco-caused disease occurring in most other nations of the world.

The views expressed in this paper are those of the author and do not reflect an official position of the US federal government or its agencies.

1 US Centers for Disease Control and Prevention. Cigarett smoking among adults - United States, 1993. MMWR smoking among

2 Lynch BS, Bonnie RJ, eds. Growing up tobacco free Preventing nicotine addiction in children. Committee on preventing nicotine addiction in children and youths, Institute of Medicine. Washington, DC: Nationa Academy Press, 1994

3 US Department of Health and Human Services. Preventing tobacco use among young people: a report of the Surgeon General. Atlanta, Georgia: Public Health Service, Centers for Disease Control and Prevention, Office on Smoking and Health, 1994. (US Government Printing Office No S/N 017-001-00491-0.)

4 Peto R, Lopez AD, Boreham J, Thun M, Heath C. Mortality from smoking in developed countries 1950-2000. Mortality from smoking in developed countrie

5 US Centers for Disease Control and Prevention. Cigarette smoking-attributable mortality and years of potential lif lost - United States, 1990. MMWR 1993; 42: 645-9.

6 Schuh LM, Henningfield JE. Nicotine replacement treatment and public health interventions: toward a marriage of two approaches. In: Slama K, ed. Tobacco and health proceedings of the ninth world conference on tobacco and health (in press)

7 US Department of Health and Human Services. The health consequences of using smokeless tobacco. A report to the consequences of using smokeless tobacco. A report to the Maryland: Public Health Service, National Institutes of Health, 1986. (NIH Publication No 86-2874.)

8 Connolly GN, Winn DM, Hecht SS, Henningfield JE, Walker B, Hoffmann D. The reemergence of smokeless tobacco. N Engl f Med 1986; 314: 1020-7.

9 Slade J, Connolly GN, Davis RM, Douglas CE, Henning field JE, Hughes JR, et al. Report of the tobacco polic research study group on tobacco products. Tobacco Control 1992; 1 (suppl): S4-9.

10 US Department of Health and Human Services. The health consequences of smoking : nicotine addiction: A report of the Surgeon General, 1988. Rockville, Maryland: Public
Health Cervice, Centers for Disease Control, Office on Smoking and Health, 1988. (DHHS Publication No (CDC) 88-8406.

11 Henningfield JE, Stapleton JM, Benowitz NL, London ED. Higher levels of nicotine in arterial than in venous blood after cigarette smoking. Drug Alcohol Depend 1993; 33: 23-9.

12 Henningfield JE, Keenan RM. Nicotine delivery kinetics and abuse liability. $\mathcal{F}$ Consult Clin Psychol 1993; 61: 743-50.

13 Breslau N, Fenn N, Peterson EL. Early initiation and nicotine dependence in a cohort of young adults. Drug Alcohol Depend 1993; 33: 129-37.

14 Robins LN, Murphy GE. Drug use in a normal population of young negro men. Am $\mathcal{F}$ Public Health 1967; 57: of young

15 Kandel DB. Issues of sequencing of adolescent drug use and other problem behaviors. Drugs Society 1989; 3: 55-76.

16 Giovino GA, Henningfield JE, Tomar SL, Escobedo LG, Slade J. Epidemiology of tobacco use and dependence. Epidemiol Rev 1995; 17: 48-65.

17 Kessler D. Nicotine addiction in young people. $N$ Engl f Med 1995; 333: 186-9.

18 Henningfield JE. Nicotine addiction. In: Substance abuse. Ross roundtable on critical issues in family medicine. Columbus, OH: Ross Products Division, 1994: 171-86.

19 George $\mathrm{H}$. Gallup International Institute. Teen-age attitudes and behavior concerning tobacco. Princeton, NJ: George H Gallup International Institute, 1992.

20 Henningfield JE, Kozlowski LT, Benowitz NL. A proposal to develop meaningful labeling for cigarettes. $\mathcal{F} A M A$ $1994 ; 272$ : 312-4.

21 Benowitz NL, Henningfield JE. Establishing a nicotine threshold for addiction. $N$ Engl F Med 1994; 331 : 123-4.

22 Hughes JR. An algorithm for smoking cessation. Arch Fam Med 1994; 3: 280-5.

23 Woody GE, McNicholas LF, Vocci F, Henningfield JE, and staff of pilot drug evaluation unit of Food and Drug Administration. Draft report to the US Food and Drug Administration. Draft report to the November 12,1992 .

24 Transdermal Nicotine Study Group. Transdermal nicotine for smoking cessation. Six-month results from two multicenter controlled clinical trials. $\mathcal{f} A M A 1991 ; 266$ : 3133-8

25 Reuter P, MacCoun RJ. Lessons from the absence of harm reduction in American drug policy. Tobacco Control 1995; 4 (suppi 2): $\overline{\mathrm{S}} 2 \overline{8}-\overline{3} 2$

26 Goldstein A. Addiction: from biology to drug policy. New York: WH Freeman and Company, 1994.

27 Hughes JR. Applying harm reduction to smoking. Tobacco Control 1995; 4 (suppl 2): S33-8.

\title{
Lessons from the absence of harm reduction in American drug policy
}

\author{
Peter Reuter ${ }^{\star}$, Robert J MacCoun
}

\section{School of Public \\ Affairs and \\ Department of \\ Criminology \\ University of \\ Maryland, Van \\ Munching Hall, \\ College Park, \\ Maryland 20742, USA \\ P Reuter}

Graduate School of

Public Policy,

University of

California, 2607

Hearst Avenue,

Berkeley, California

94720-7320, USA

R J MacCoun

Correspondence to P Reuter PhD

$\star$ Dr Reuter delivered this paper at the conference.
Even among its supporters, the American drug control strategy provides few grounds for enthusiasm. Despite many indications that the prevalence of drug use has declined over the past decade, in many ways the severity of the drug problem has remained fairly constant. ${ }^{1}$ Moreover, our current mix of policies is expensive, intrusive, and may actually contribute to drug related harm. ${ }^{2}$ Thus there is considerable interest - as documented by a steady stream of popular books, television programmes, and analytic and newspaper essays - in looking at a much wider array of drug control strategies, including approaches that go well beyond simply tinkering at the edges of existing programmes.

In this essay we shall provide a brief overview of one such alternative approach, the harm reduction paradigm. ${ }^{3-5}$ We shall discuss its influence in Western Europe and the barriers to its diffusion into American policy towards illicit drugs, and we shall offer a framework highlighting ways in which harm reduction might be integrated into the under- lying logic of American drug control. Finally we tentatively suggest its relevance to smoking policy.

\section{Drug policy and drug related harms}

The American "drug problem" is in fact constituted by quite a variegated list of harms. ${ }^{6}$ The table provides a partial listing intended to illustrate the diversity.

Some harmful effects are undoubtedly a direct function of drug use itself, and particularly of dependence. But much of the harm is attributable to the criminal distribution of drugs. Certainly the violence in drug selling and the development of a large criminal economy ${ }^{8}$ are functions of the conditions that we have created around drug selling, rather than any psychopharmacological characteristics of the drugs per se. It is not implausible that a prohibition on chocolate might lead to markets with potential for violence; such an inference is even more plausible with respect to cigarettes. Prohibition-related ill-effects are 